\title{
Seroprevalence of hepatitis B virus co-infection among HIV-1-positive patients in North-Central Nigeria: The urgent need for surveillance
}

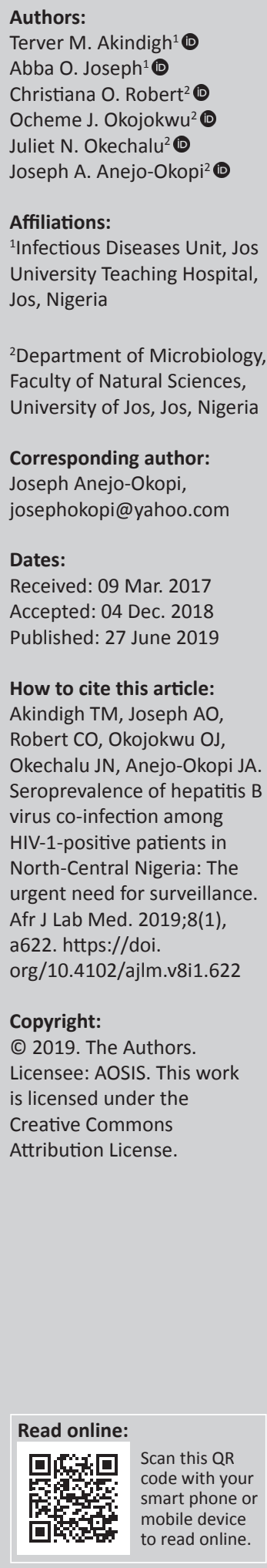

We report the seroprevalence of hepatitis B surface antigen among HIV-positive patients at a clinic in North-Central Nigeria. Screening for hepatitis B virus was based on serological markers. Alanine aminotransferase levels and CD4+ T-lymphocyte counts were compared between patients. The study showed that $9.2 \%$ were positive for hepatitis B surface antigen with significant differences between alanine aminotransferase levels of patients with and without hepatitis B virus. We recommend a national surveillance system to monitor control efforts.

Keywords: Antiretroviral therapy; Alanine aminotransferase; CD4+ T-lymphocytes; hepatitis B virus; HIV; Serological markers.

\section{Introduction}

Hepatitis B virus (HBV), a circular DNA virus with humans serving as the only reservoir ${ }^{1}$, remains a worldwide public health problem. Transmission of the virus occurs via exposure to infected blood and body fluids. ${ }^{1}$ In areas where the prevalence of hepatitis B surface antigen (HBsAg) is more than $8 \%$, there are two broad possibilities for how transmission can occur: either it happens vertically at birth from chronically infected mothers to their newborns or horizontally during childhood or in adulthood. ${ }^{2,3}$ The infection caused by the virus is among the leading causes of liver disease, with liver-related deaths occurring in an estimated $25 \%-30 \%$ of the population of chronic carriers, principally cirrhosis and hepatocellular carcinoma. ${ }^{4}$

A fifth of the current global population is estimated to be seropositive for HBsAg. ${ }^{5}$ As at 2013, an estimated $13.6 \%$ of the Nigerian population had been reported to be chronic carriers of HBsAg. ${ }^{6}$ Consequently, the burden of disease is considered to be high, as evidenced by the high incidence of morbidity and mortality associated with the virus. ${ }^{7}$

The similarity in transmission routes for HBV and HIV makes co-infection very common. ${ }^{8} \mathrm{HBV} /$ HIV co-infection has been shown by some studies to increase morbidity and mortality when compared to HIV mono-infection. ${ }^{9,10}$ It has been reported that co-infection facilitates replication and decreases clearance of both viruses, as a result of impaired innate and adaptive immune responses. ${ }^{11,12}$

The HIV-positive sub-population deserves attention, considering the enormous public health consequences that co-infection with $\mathrm{HBV}$ can have. This cross-sectional study reports the prevalence of HBV infection among HIV-positive patients receiving treatment and care from the Jos University Teaching Hospital (JUTH), Infectious Diseases Unit.

\section{Methods}

\section{Ethical considerations}

Approval of the study protocol was obtained from the Institutional Ethics Committee at JUTH (study approval number, JUTH/DCS/ADM/127/XIX/5967).

\section{Study population}

This laboratory-based study was carried out by examining 120 HIV patients older than 18 years on highly active antiretroviral therapy accessing care at JUTH who provided written informed consent. The sample size was determined using the following formula: ${ }^{13}$ 
where

$\mathrm{z}=$ Alpha at $95 \%$ confidence level $=1.96$

$\mathrm{p}=$ prevalence of hepatitis $\mathrm{B}$ virus infection $^{14}=7.2 \%=0.072$

$\mathrm{q}=0.928$

$\mathrm{e}=$ margin of error $=0.05$

$\mathrm{N}=$ minimum sample size $=10.2$ with $10 \%$ attrition $=10.2$, thus $N=20$

\section{Collection of patients' blood}

Whole blood samples were obtained from each patient and used for screening for HBV serological markers as well as for performing cluster of differentiation CD4+ T-lymphocyte enumeration and clinical chemistry analysis of alanine aminotransferase (ALT). The process involved collection of blood using a BD Precision Glide ${ }^{\mathrm{TM}}$ into a $4 \mathrm{~mL}$ EDTA BD Vacutainer $^{\circledR}$ (Becton Dickinson, Plymouth, United Kingdom) for CD4+ T-lymphocyte enumeration and into a $6 \mathrm{~mL} \mathrm{BD}$ Vacutainer $^{\circledR}$ Clot Activator Tube (Becton Dickinson, Plymouth, United Kingdom).

\section{Serological marker assay}

Plasma was obtained by centrifuging collected whole blood at $2500 \mathrm{rpm}$ for $1 \mathrm{~min}$ and testing for hepatitis B serologic markers, including the surface antigen (HBsAg), surface antibody (Anti HBs), envelope antigen (HBeAg), envelope antibody (Anti HBe) and core antibody (Anti $\mathrm{HBc}$ ) of viral particles as performed using the Rapid HBV COMBO test kit (Acumen diagnostics Incorporated, China) according to the manufacturer's instructions.

\section{CD4+ T-lymphocyte enumeration}

CD4+ T-lymphocyte counts for each patient were obtained by adding $20 \mu \mathrm{L}$ of the patient's whole blood to $20 \mu \mathrm{L}$ of CD4+ easy count kit monoclonal antibody, then incubating in the dark for $15 \mathrm{~min}$. Afterwards, $800 \mu \mathrm{L}$ of CD4+ easy count kit no lyse buffer was added to the incubated mixture and analysed using a Partec CyFlow cytometer (Sysmex-Partec, Munster, Germany).

\section{Evaluation of alanine aminotransferase}

ALT levels were obtained using a COBAS C311 (Roche Diagnostics, Mannheim, Germany) chemistry auto-analyser. The method involved using an Eppendorf 5708 centrifuge to spin the blood sample and obtain an aliquot of serum, which was then placed in a sample cup and processed using the COBAS C311 auto-analyser to determine the serum ALT levels of patients.

\section{Data analysis}

Data were analysed using SPSS version 17 (IBM Corporation, Armonk, New York, United States) to obtain descriptive statistics, evaluate associations between socio-demographic variables and positivity for HBV. We also determined whether there was a difference between ALT and CD4+ counts using an unpaired $t$-test for the mean values of both groups. Decisions on statistical significance were made at a $5 \%$ level of significance.

\section{Results}

Out of the 120 patients on highly active antiretroviral treatment who participated in the study, 88 (73.3\%) were women and $32(26.7 \%)$ were men (Table 1). Participants in this study had a mean age of $40.4 \pm 10.6$ years with male participants significantly older than their female counterparts in the study. Similarly, the ALT levels of male participants were significantly higher than female participants.

Among the HIV-positive patients in the study, 11 were positive for HBsAg (9.2\%) (Table 2). For the other serological markers in the study, 15 patients $(12.5 \%)$ were positive for Anti HBs 1 patient $(0.8 \%)$ was positive for $\mathrm{HBeAg}, 27$ patients (22.5\%) were positive for Anti HBe, and 32 patients (26.7\%) were positive for Anti HBc.

Being in the 40-49-year age group was significantly associated with HBV / HIV co-infection ( $p=0.019)$ (Table 3$)$. Our study reported a higher rate of HBV infection among the male HIV patients $(12.0 \%$ versus $7.9 \%$ in female patients), but this observation was not significant ( $p=$ 0.494). The associations of HBV infection with age, educational level and marital status were also not statistically significant. No association between infection and marital status ( $p=0.875$ ) when they were compared to patients who were negative for HBsAg.

The mean CD4+ counts of HIV/HBV co-infected patients were lower than patients who were only positive for HIV; this difference was not statistically significant $(p=0.938)$ (Table 3). However, the mean ALT values for patients positive for HBsAg were significantly higher than for patients negative for $\mathrm{HBsAg}(p=0.033)$.

TABLE 1: Patient characteristics by sex, Jos University Teaching Hospital HIV clinic, August 2015.

\begin{tabular}{lccc}
\hline General characteristics & Men & Women & $p$ \\
\hline Sex & 32 & 88 & - \\
$N$ & 26.7 & 73.3 & - \\
$\%$ & & & \\
Age in years & $47.2 \pm 11.5$ & $37.9 \pm 9.1$ & $<0.0001$ \\
$\quad$ Mean \pm SD & & & \\
CD4+ cell count (cells $/ \mu \mathrm{L}) \dagger$ & $188.1 \pm 168.1$ & $237.8 \pm 191.4$ & 0.199 \\
$\quad$ Mean \pm SD & & & \\
ALT level $(I U / m L) \dagger$ & $35.6 \pm 28.2$ & $23.7 \pm 21.9$ & 0.02 \\
$\quad$ Mean $\pm S D$
\end{tabular}

$\dagger$, unpaired $t$-test.

ALT, Alanine aminotransferase; SD, Standard deviation.

TABLE 2: Seroprevalence of hepatitis B serological markers $†$ among HIV-positive adult patients attending the Jos University Teaching Hospital HIV clinic, August 2015

\begin{tabular}{lcccccc}
\hline Serological marker & \multicolumn{2}{c}{ Positive } & & \multicolumn{2}{c}{ Negative } \\
\cline { 2 - 3 } \cline { 6 - 7 } & $\boldsymbol{n}$ & $\mathbf{\%}$ & & $\boldsymbol{n}$ & $\%$ \\
\hline Hepatitis B surface antigen & 11 & 9.2 & & 109 & 90.8 \\
Hepatitis B surface antibody & 15 & 12.5 & & 105 & 87.5 \\
Hepatitis B envelope antigen & 1 & 0.8 & & 119 & 99.2 \\
Hepatitis B envelope antibody & 27 & 22.5 & & 93 & 77.5 \\
Hepatitis B core antibody & 32 & 26.7 & & 88 & 73.3 \\
\hline
\end{tabular}


TABLE 3: Socio-demographic characteristics and laboratory parameters of HBV infection among HIV-positive adult patients, Jos University Teaching Hospital HIV clinic, August 2015

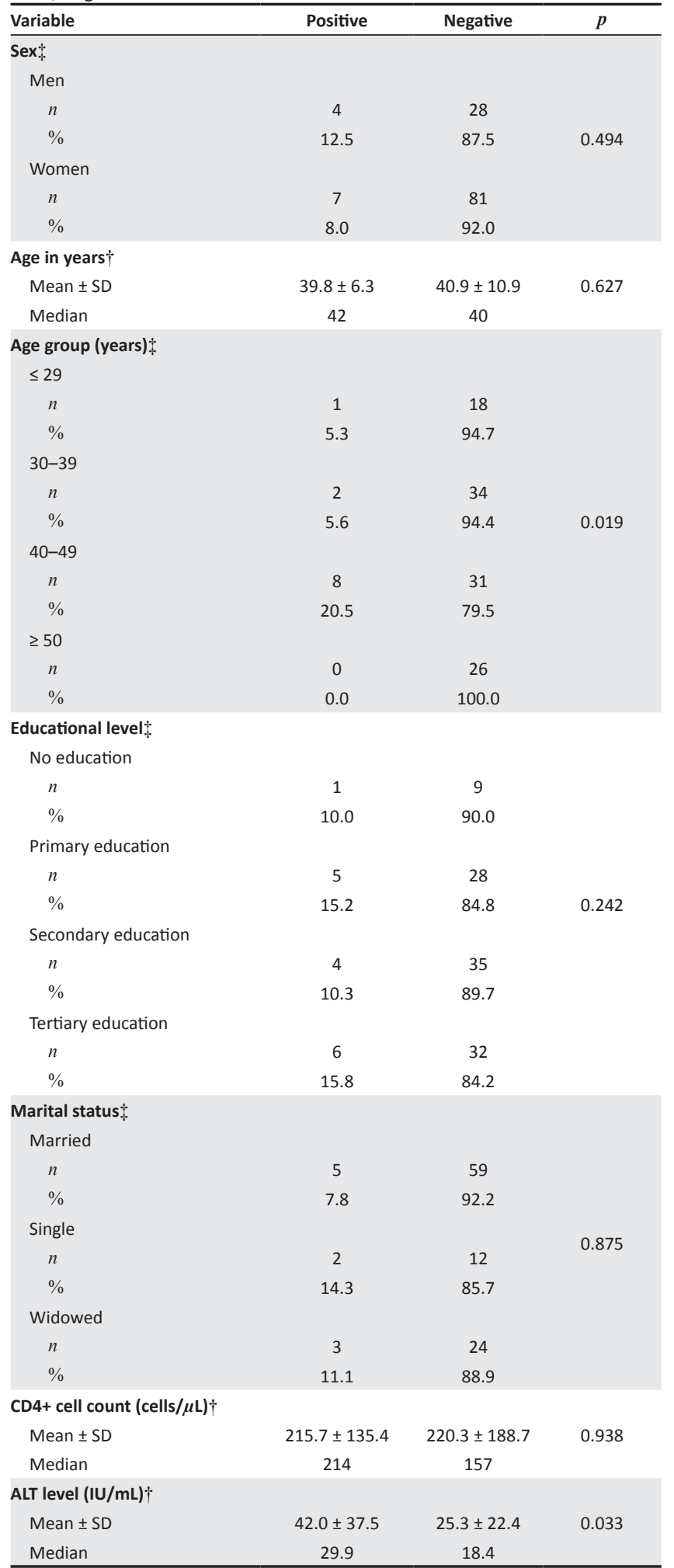

Note: Fifteen participants did not provide a response for marital status.

ALT, Alanine aminotransferase; CD4+, cluster of differentiation.

$\dagger$, unpaired $t$-test.

$\$$, Chi-square distribution.

\section{Discussion}

This present study observed a 9.2\% sero-prevalence of HBsAg among HIV-positive patients attending the HIV treatment clinic at JUTH. This is slightly lower than the $12.5 \%$ prevalence reported from north-western Nigeria in $2013^{15}$ and the $11.5 \%$ observed in 2012 another health facility in North-Central Nigeria. ${ }^{16}$ However, another study conducted in southwestern Nigeria reported a much lower prevalence of $5.7 \%$ among HIV-positive patients in 2009. ${ }^{17}$ These reports which show differences in regional prevalence may point to different epidemiological factors at work in different parts of the country and reveal a gap in our current understanding of the epidemiology of HIV / HBV co-infection. National surveillance systems to provide a full picture of the co-infection landscape are urgently needed to identify epidemiological trends over time to make sure suitable prevention measures are deployed.

Our results agree with the conclusions of a recent metaanalysis by Musa and colleagues ${ }^{6}$ that showed that in Nigeria, there is a continued decline in prevalence of hepatitis B infection; they estimated that the rate of decline has been approximately $0.8 \%$ annually. While our finding provides significant feedback regarding the impact of the HBV vaccination programme in Nigeria, the result remains higher than the $8 \%$ threshold that the World Health Organization considers endemic among HIV-positive individuals. We made an observation similar to other studies regarding men having higher rates of infection than women. ${ }^{17,18}$ The report of a recent study by Akhtar et al. ${ }^{19}$ in a tertiary hospital in Malaysia and another report from north-east Nigeria ${ }^{20}$ for HBV co-infection in HIV patients agree with our observation of an age-specific association in patients aged $40-49$ years. A global age-specific prevalence, which is highest in subSaharan Africa, has been reported from a systematic review of data on worldwide prevalence collected over a 27-year period..$^{21}$ The association between increasing age and being positive for HBsAg by several workers reinforces the current paradigm that the epidemiology of $\mathrm{HBV}$ in Nigeria is primarily via horizontal transmission. ${ }^{22}$ In the present study, serum ALT levels in patients who were positive for $\mathrm{HBsAg}$ were significantly higher than ALT levels in patients who were HBsAg-negative, which is a comparable observation to that made by Otegbayo et al. ${ }^{23}$ It is possible that the patients in our study population were in the late reactivation phase where high serum ALT levels accompany progressive liver damage. ${ }^{24}$ There is a growing interest in understanding serum HBsAg levels across the different phases of HBV infection. ${ }^{25}$ However, our inability to quantify HBsAg titers and ascertain the different phases of infection are limitations of our study. Although two studies documenting the natural history of the infection in Asian and European cohorts reported no significant association between ALT activity and serum HBsAg titers, ${ }^{26,27}$ an African perspective for the different phases may reveal a different picture in the course of infection.

\section{Conclusion}

Despite the overall decline in $\mathrm{HBV}$ prevalence, it remains endemic in HIV-positive populations and requires effective surveillance to fully understand the epidemiology of HIV/ $\mathrm{HBV}$ co-infection in Nigeria. Increased uptake of a vaccination programme among HIV-positive patients who are susceptible 
to HBV infection, along with the identification of patients with HBV infection for treatment, are critical strategies in prevention and control activities.

\section{Acknowledgements}

We are grateful to the management of the JUTH Infectious Diseases Unit for their support and also to the entire staff of the centre for their cooperation and technical contributions to this study.

\section{Competing interests}

The authors declare that they have no financial or personal relationships that may have inappropriately influenced them in writing this article.

\section{Authors' contributions}

This work was carried out in collaboration between all authors. Author T.M.A. performed data analysis and result interpretation, prepared the tables, wrote the final manuscript and reviewed the final draft. C.O.R. \& A.O.J. designed and performed the experiments, and wrote and reviewed manuscript. J.A.A.-O. conceptualised the experiment protocol, supervised the experiments and reviewed the final draft of the manuscript. J.N.O. and O.J.O. reviewed the manuscript and made corrections to manuscript. All authors read and approved the final manuscript.

\section{Source of support}

None.

\section{References}

1. Hwang EW, Cheung R. Global epidemiology of Hepatitis B virus (HBV) infection. N Am J Med Sci. 2011;4(1):7-13. https://doi.org/10.7156/v4i1p007

2. Kiire CF. The epidemiology and prophylaxis of hepatitis B in sub-Saharan Africa: A view from tropical and subtropical Africa. Gut. 1996;38(Suppl 2):S5-S12. https:// doi.org/10.1136/gut.38.Suppl_2.S5

3. Hoffmann $\mathrm{CJ}$, Thio $\mathrm{CL}$. Clinical implications of HIV and hepatitis B co-infection in Asia and Africa. Lancet Infect Dis. 2007;7:402-409. https://doi.org/10.1016/ S1473-3099(07)70135-4

4. Bosch FX, Ribes J, Diaz M, Cléries R. Primary liver cancer: World-wide incidence and trends. Gastroenterol. 2004;127(5 Suppl 1):S5-S16. https://doi.org/10.1053/j. gastro.2004.09.011

5. Sharma SKJ, Saini N, Chwla Y. Hepatitis B. Virus: In active. Curr Immunol J. 2005;2:82.

6. Musa BM, Bussell S, Borodo MM, Samaila AA, Femi OL. Prevalence of hepatitis B virus infection in Nigeria, 2000-2013: A systematic review and meta-analysis. Niger J Clin Pract. 2015;18(2):163-172. https://doi.org/10.4103/1119-3077.151035
7. Lok A. Hepatitis B virus infection and liver transplantation. J Virol. 2005;24: 112-114.

8. Alter MJ. Epidemiology of viral hepatitis and HIV co-infection. J Hepatol. 2006;44: S6-S9. https://doi.org/10.1016/j.jhep.2005.11.004

9. Ockenga J, Tillmann HL, Trautwein C, Stoll M, Manns MP, Schmidt RE. Hepatitis $B$ and C in HIV-infected patients. Prevalence and prognostic value. J Hepatol. 1997;27:18-24. https://doi.org/10.1016/S0168-8278(97)80274-7

10. Pouti M, Torti C, Bruno R, Filice G, Carosi G. Natural history of chronic hepatitis B in co-infected patients. J Hepatol. 2006;44:S65-S70. https://doi.org/10.1016/j. jhep.2005.11.015

11. Sulkowski MS, Thomas DL, Chaisson RE, Moore RD. Hepatotoxicity associated with antiretroviral therapy in adults infected with human immunodeficiency virus and the role of hepatitis C or B virus infection. J Am Med Assoc. 2000;283(1):74-80. https://doi.org/10.1001/jama.283.1.74

12. Hoffmann $\mathrm{CJ}$, Charalambous $\mathrm{S}$, Thio $\mathrm{CL}$, et al. Hepatotoxicity in an African antiretroviral therapy cohort: The effect of tuberculosis and hepatitis B. AIDS. 2007;21(10):1301-1308. https://doi.org/10.1097/QAD.0b013e32814e6b08

13. Singh AS, Masuku MB. Sampling Techniques and Determination of Sample size in Applied Statistics Research: An Overview. International Journal of Economics, Commerce and Management. 2014;2(11).

14. Solomon O, Mahafroz K, Mashor M, Arome F, Neha D. Prevalence of HBV among students at staff at the University of Jos, Nigeria: Results from a medical outreach screening programme. Int J Sci Res. 2014; 4(11)::1-5

15. Hamza M, Samaila AA, Yakasai MA, et al. Prevalence of hepatitis $B$ and $C$ virus infection among HIV-infected patients in a tertiary hospital in North-Western Nigeria. Niger J Bas Clin Sci. 2013;10:7-81. https://doi.org/10.4103/0331 8540.122765

16. Tremeau-Bravard A, Ogbukagu IC, Ticao CJ, Abubakar JJ. Seroprevalence of hepatitis B and C among HIV-positive population in Abuja, Nigeria. Afr J Health Sci. 2012;12(3):312-317.

17. Adewole OO, Anteyi E, Ajuwon Z, et al. Hepatitis B and C virus co-infection in Nigerian patients with HIV infection. J Infect Dev Ctries. 2009;3(5):369-375. https://doi.org/10.3855/jidc.245

18. Opaleye OO, Oluremi AS, Ogbolu DO, Babalola BA, Shittu B, Adesiyan AA Prevalence of hepatitis-B virus infection among HIV patients in Ikole Ekiti, South-Western Nigeria. Asia Pac J Health Sci. 2014;1(4):507-511. https://doi. org/10.21276/apjhs.2014.1.4.35

19. Akhtar A, Khan AH, Sulaiman SA, Soo CT, Khan K. HBV and HIV co-infection: Prevalence and clinical outcomes in tertiary care hospital Malaysia. J Med Virol. 2016;88:455-460. https://doi.org/10.1002/jmv.24347

20. Mustapha SK, Jibrin YB. The prevalence of Hepatitis B surface antigenaemia in patients with human immunodeficiency virus (HIV) infection in Gombe, Nigeria. Ann Afr Med. 2004;3(1):10-12.

21. Ott JJ, Stevens GA, Groeger J, Wiersma S. Global epidemiology of hepatitis B virus infection: New estimates of age-specific HBsAg seroprevalence and endemicity. Vaccine 2012;30(12):2212-2219. https://doi.org/10.1016/j.vaccine. 2011.12.116

22. Ikobah J, Okpara $H$, Elemi I, Ogarepe $Y$, Udoh $E$, Ekanem $E$. The prevalence of hepatitis $B$ virus infection in Nigerian children prior to vaccine introduction into the national programme on immunization schedule. Pan Afr Med J. 2016;23:128, 1-9. https://doi.org/10.11604/pamj.2016.23.128.8756

23. Otegbayo JA, Taiwo BO, Akingbola TS, et al. Prevalence of hepatitis B and C positivity in a Nigerian cohort of HIV-infected patients. Ann Hepatol. 2008;7(2):152-156.

24. Vigano $M$, Lampertico P. Clinical implications of HBsAg quantification in patients with chronic hepatitis b. Saud J Gastroenterol. 2012;18(2):81-86. https://doi. org/10.4103/1319-3767.93805

25. Chan HL, Wong VW, Tse AM, et al. Serum hepatitis B surface antigen quantitation can reflect hepatitis B virus in the liver and predict treatment response. Clin Enterol Hepatol. 2007;5:1462-1468. https://doi.org/10.1016/j.cgh.2007.09.005

26. Jaroszewicz J, Serrano BC, Wursthorn K, et al. Hepatitis B surface antigen levels in the natural history of hepatitis B virus (HBV) infection: A European perspective. J Hepatol. 2010;52:514-522. https://doi.org/10.1016/j.jhep.2010.01.014

27. Nguyen T, Thompson AJV, Bowden S, et al. Hepatitis B surface antigen levels during the natural history of chronic hepatitis: A perspective on Asia. J Hepatol. 2010;52:508-513. https://doi.org/10.1016/j.jhep.2010.01.007 